\title{
Investigation of Free Liquid Oscillations in a Bounded Basin Representing an Approximate Model of the Sea of Azov
}

\author{
Yu.V. Maniliuk, L.V. Cherkesov
}

\author{
Marine Hydrophysical Institute, Russian Academy of Sciences, Sevastopol, \\ Russian Federation \\ e-mail: uvmsev@yandex.ru
}

\begin{abstract}
Based on the analytic solution of long wave equations, the features of seiches and seiche-like oscillations (combination of different seiche modes) in the model basin, which has the characteristic size of the Azov Sea, are considered.

It was found that fluctuations of sea level forced by seiche-like oscillations are strongly different from the ones of the level due to seiche oscillations. Seiche-like fluctuations have a single level nodal line which changes its position in time, turning counter-clockwise. The maximum elevation level in the selected areas of the basin approached to the maximum possible value which is equal to the sum of the amplitudes of the interacting waves in the initial moment of time. The maximum value of the velocity modulus of the wave flows in all the cases was significantly less than the maximum possible value.

At seiche oscillations the currents have a direction which is constant during the half-period and then it changes into the opposite one. Also the presence of counter and diverging flows is characteristic of seiches. In case of seiche-like oscillations the direction of wave currents always changes with time, velocity vectra are turning clockwise at that. Counter and diverging flows are absent.
\end{abstract}

Keywords: seiches, seiche-like oscillations, free waves, long waves, currents, the Sea of Azov, analytic solution.

DOI: $10.22449 / 1573-160 X-2016-2-14-23$

(C) 2016, Yu.V. Maniliuk, L.V. Cherkesov

(C) 2016, Physical Oceanography

Introduction. Seiches are one of the most common phenomena in bounded basins and they make a significant contribution to the formation of hydrologic regimes in these basins [1,2]. This is due to the fact that there is a great number of causes that induce seiches, and a small amount of energy is required to generate them $[2,3]$.

An initial change of liquid level, which transforms into the oscillations (they represent a superposition of several seiche modes) after the termination of perturbation effect, occurs as a result of exciting force effect. We are to call them seiche-like oscillations of liquid.

In real basins theoretical investigation of seiches is hampered by their complex geometric shape and variable depth. Therefore it is impossible to find analytical solutions of hydrodynamic equations for these basins yet, but it is possible to solve this problem numerically using two approaches. In the first approach the perturbing force effect (after the termination of this force fluctuations of liquid in the basin are studied) on basin surface is modeled. Perturbations may have different forms: cyclone [4]; moving baric front [5]; wave-generator (which generates waves at resonant frequencies) at the liquid boundary of basin [6]; wind fields [7]. However, it is unknown from what the resultant oscillations are formed. It is assumed that this oscillation is a superposition of several seiche modes. Using the second approach, a problem on eigenvalues is solved numerically. A broad set of different methods is also used here. These methods are the following: finite difference 
method [8]; finite element method [9]; $R T$-algorithm of conformal mapping. Thus, in [9] the problem solution on eigenvalues was found for the Sea of Azov by finite element method. As a result, the periods were calculated and the spatial structure of seiche modes was determined.

Analytic solutions allow us to obtain a more complete picture of the phenomenon and investigate it in more detail. In [11 - 13] the formulas for calculation of seiche periods and free surface deviations for several basins with simple shape are given. From all the basins for which an analytic solution can be found, a rectangular basin with constant depth has a shape that is the most similar to the one of the Sea of Azov.

The objective of this paper is to find such an analytic solution of seiche problem in linear approximation for rectangular basin of constant depth, which would allow us to calculate the periods of seiche oscillation modes, free surface deviations and the velocities of wave currents. Seiche and seiche-like oscillations are investigated on the basis of obtained solution. In [14] it is shown that the lowest modes of barotropic seiches can occur after the baric front passage over the AzovBlack Sea basin. Therefore, we considered seiche-like oscillations which represent a superposition of the first two seiche modes.

Formulation of the problem and obtaining of analytic solution. Let us consider free oscillations of homogeneous liquid in a closed basin. We assume that the waves are long and the atmospheric pressure above the basin waters is constant. In such a case, liquid motion is described by the following system of equations [15]

$$
u_{t}=-g \zeta_{x}, v_{t}=-g \zeta_{y}, \zeta_{t}=-(h u)_{x}-(h v)_{y},
$$

where $x, y$ are the Cartesian coordinates; $u, v$ are the projections of liquid motion velocity vector on the $x, y$ axes, respectively; $\zeta$ is free surface deviation; $h$ is a depth of the basin; $t$ is time; $g$ is a free fall acceleration.

At the rigid sidewalls of the basin an impermeability condition should be satisfied

$$
V_{n}=0 .
$$

Here $V_{n}$ is normal to the sidewall of the basin velocity component.

We are to consider rectangular basin with a constant depth $h$. The length of the basin is $a$, the width is $b$. Taking this into account, boundary conditions (2) will take the following form:

$$
u(0, y)=0, u(a, y)=0 ; v(x, 0)=0, v(x, b)=0 .
$$

We will seek a solution of the system (1) in a form of time-periodic functions which satisfy the boundary conditions (3):

$$
\begin{gathered}
u_{k m}(x, y, t)=\bar{u}_{k m}(y) \sin \left(k \pi x a^{-1}\right) \sin \sigma_{k m} t, \\
v_{k m}(x, y, t)=\bar{v}_{k m}(x) \sin \left(m \pi y b^{-1}\right) \sin \sigma_{k m} t, \\
\zeta_{k m}(x, y, t)=\bar{\zeta}_{k m}(x, y) \cos \sigma_{k m} t,
\end{gathered}
$$

where $\sigma_{k m}$ is a frequency of liquid oscillations, $k=0,1,2, \ldots, ; m=0,1,2, \ldots$,

Now, having plugged in (4) into the system (1), we obtain

$$
\frac{\partial \bar{\zeta}_{k m}(x, y)}{\partial x}=-\frac{\sigma_{k m}}{g} \bar{u}_{k m}(y) \sin \frac{k \pi x}{a},
$$




$$
\frac{\partial \bar{\zeta}_{k m}(x, y)}{\partial y}=-\frac{\sigma_{k m}}{g} \bar{v}_{k m}(x) \sin \frac{m \pi y}{b} .
$$

Integrating the equations (5) with respect to $x$ and (6) with respect to $y$, we have

$$
\begin{aligned}
& \bar{\zeta}_{k m}(x, y)=\frac{\sigma_{k m} a}{g k \pi} \bar{u}_{k m}(y) \cos \frac{k \pi x}{a}, \\
& \bar{\zeta}_{k m}(x, y)=\frac{\sigma_{k m} b}{g m \pi} \bar{v}_{k m}(x) \cos \frac{m \pi y}{b} .
\end{aligned}
$$

We are to seek $\bar{u}_{k m}(y)$ and $\bar{v}_{k m}(x)$ in the following form:

$$
\bar{u}_{k m}(y)=u_{0 k m} \cos \left(m \pi y b^{-1}\right), \quad \bar{v}_{k m}(x)=v_{0 k m} \cos \left(k \pi x a^{-1}\right) .
$$

Here $u_{0 k m}, v_{0 k m}$ are the amplitudes of velocity components.

Setting the right parts of equations (7), (8) equal to each other and replacing $\bar{u}_{k m}(y)$ and $\bar{v}_{k m}(x)$ with the expression from (9), we are to find the relation between the amplitudes of velocity components:

$$
v_{0 k m}=\frac{a m}{b k} u_{0 k m} .
$$

Taking into account (4), (8), from the third equation of system (1) we will obtain:

$-\frac{\sigma_{k m}^{2} a}{g k \pi} u_{0 k m} \cos \frac{k \pi x}{a} \cos \frac{m \pi y}{b} \sin \sigma_{k m} t=-h \pi u_{0 k m}\left(\frac{k}{a}+\frac{m^{2} a}{k b^{2}}\right) \cos \frac{k \pi x}{a} \cos \frac{m \pi y}{b} \sin \sigma_{k m} t$

Hence we find the expression for the calculation of seiche oscillation frequencies of liquid in the rectangular basin of constant depth:

$$
\begin{gathered}
\sigma_{k m}=\pi \sqrt{g h} \sqrt{\frac{k^{2}}{a^{2}}+\frac{m^{2}}{b^{2}}}, \\
\tau_{k m}=\frac{2}{\sqrt{g h}} \frac{a b}{\sqrt{k^{2} b^{2}+m^{2} b^{2}}} .
\end{gathered}
$$

With regard to (7), (9), formula (4) will take the following form:

$$
\zeta_{k m}(x, y, t)=\frac{\sigma_{k m} a}{g k \pi} u_{0 k m} \cos \frac{k \pi x}{a} \cos \frac{m \pi y}{b} \cos \sigma_{k m} t .
$$

The expression (13) may be written as follows:

$$
\zeta_{k m}(x, y, t)=\zeta_{0 k m} \cos \frac{k \pi x}{a} \cos \frac{m \pi y}{b} \cos \sigma_{k m} t,
$$

where $\zeta_{0 \mathrm{~km}}$ is an amplitude of free surface deviation.

Formula (14) allows us to find a profile of liquid free surface for the specified values of $k, m, \zeta_{0 \mathrm{~km}}$ and geometric parameters of the basin $a, b$.

Using (13) and (14), we will obtain

$$
\zeta_{0 k m}=\frac{\sigma_{k m} a}{g k \pi} u_{0 k m} .
$$

With regard to (11), the relation (15) will take the following form:

$$
\zeta_{0 k m}=\frac{a}{k} u_{0 k m} \sqrt{\frac{h}{g}} \sqrt{\frac{k^{2}}{a^{2}}+\frac{m^{2}}{b^{2}}} .
$$


Hence we have the formula for calculation of $u_{0 k m}$ values by the specified value $\zeta_{0 k m}$ :

$$
u_{0 k m}=\zeta_{0 k m} \sqrt{\frac{g}{h}} \frac{k b}{\sqrt{k^{2} b^{2}+m^{2} a^{2}}} .
$$

Substituting the expression (17) to the (10), we will obtain a formula for calculation of $v_{0 \mathrm{~km}}$ by the specified value $\zeta_{0 \mathrm{~km}}$ :

$$
v_{0 k m}=\zeta_{0 k m} \sqrt{\frac{g}{h}} \frac{m a}{\sqrt{k^{2} b^{2}+m^{2} a^{2}}} .
$$

We are to write down the formulas for calculation of wave velocity components applying (4), (9), (17) and (18):

$$
\begin{aligned}
& u_{k m}(x, y, t)=\zeta_{0 k m} \sqrt{\frac{g}{h}} \frac{k b}{\sqrt{k^{2} b^{2}+m^{2} a^{2}}} \sin \frac{k \pi x}{a} \cos \frac{m \pi y}{b} \sin \sigma_{k m} t, \\
& v_{k m}(x, y, t)=\zeta_{0 k m} \sqrt{\frac{g}{h}} \frac{m a}{\sqrt{k^{2} b^{2}+m^{2} a^{2}}} \cos \frac{k \pi x}{a} \sin \frac{m \pi y}{b} \sin \sigma_{k m} t .
\end{aligned}
$$

Thus, the solution of equation system of long waves for the rectangular basin of constant depth was obtained. This solution allows us to find the periods of seche oscillation modes by the formula (12) as well as, specifying initial values of amplitudes of free surface deviations $\zeta_{0 \mathrm{~km}}$, to calculate free surface deviations on the basis of the relationship (14) and wave velocities of corresponding modes applying the expressions (19), (20).

Seiche oscillations. The analysis of the formulas (14), (19) and (20) allow us to devide seiches into three types. A type is determined by the values of $k, m$ indices. The first type seiches have $k \neq 0, m=0$, and their $u, v, \zeta$ don't depend on $y$-coordinate. The second type seiches have $k=0, m \neq 0$ and their $u, v, \zeta$ don't depend on $x$-coordinate. The third type seiches have $k \neq 0, m \neq 0$, and their $u, v, \zeta$ depend both on $x$ and $y$ coordinates.

The number of level nodal lines of each seiche mode is equal to the sum of indices $k+m$. The number of nodal lines parallel to $y$ axis is equal to $k$, and the number of nodal lines parallel to $x$ axis is equal to $m$.

Now we are to consider the peculiarities of wave motions which take place for all the above mentioned types of seiches. The calculations were carried out for the rectangular basin with $450 \mathrm{~km}$ length, $250 \mathrm{~km}$ width and $10 \mathrm{~m}$ depth. The basin is an approximate model of the Sea of Azov with its characteristic dimensions.

The values of seiche periods and maximum values of wave current velocity module, calculated according to the formula $\left|\mathbf{V}_{k m}\right|=\sqrt{u_{k m}^{2}+v_{k m}^{2}}$ for the amplitude of free surface deviation (which is equal to $0.3 \mathrm{~m}$ ), for the eight modes of seiche oscillations are represented in the table.

As is clear from the table, the longest period (which is equal to $25.25 \mathrm{~h}$ ) belongs to longitudinal uninodal seiche. The periods of other modes are signifigantly shorter: $14.03 \mathrm{~h}$ (uninodal transversal seiche), $12.63 \mathrm{~h}$ (binodal longitudinal seiche), $12.26 \mathrm{~h}$ (binodal longitudinal-transversal seiche). The periods of the third $(12.63 \mathrm{~h})$ and the fourth $(12.26 \mathrm{~h})$ seiches insignificantly differ from each other. This indicates that it is not always possible to identify seiche oscillation 
modes by the duration of their periods unambiguously. Wave current maximum velocities of uninodal and binodal seiches of the first $(k \neq 0, m=0)$ and the second ( $k=0, m \neq 0$ ) types are equal to $0.29 \mathrm{~m} / \mathrm{s}$. Wave current maximum velocities of the third type seiches $(k \neq 0, m \neq 0)$ are always lower than the ones of the first and the second type seiches. From all the considered seiches of the third type, the highest wind current velocity, equal to $0.28 \mathrm{~m} / \mathrm{s}$, belongs to the seventh mode ( $k=1, m=2$ ), and the lowest, equal to $0.22 \mathrm{~m} / \mathrm{s}$, belongs to the fifth mode ( $k=2, m=1)$. Wave current maximum velocities of seiches $((k=1, m=1)$ and $(k=2, m=2)$ ) (they have an equal number of nodal lines which are transversal both to $x$ and $y$-axis) are equal to each other and make up $0.26 \mathrm{~m} / \mathrm{s}$.

\section{Seiche periods and maximum values of wave current velocity module}

\begin{tabular}{c|c|c|c|c}
\hline Mode number & Period, $\mathrm{h}$ & $k$ & $m$ & $\left|\mathbf{V}_{k m}\right|^{\max }, \mathrm{m} / \mathrm{s}$ \\
\hline 1 & 25.25 & 1 & 0 & 0.29 \\
2 & 14.03 & 0 & 1 & 0.29 \\
3 & 12.63 & 2 & 0 & 0.29 \\
4 & 12.26 & 1 & 1 & 0.26 \\
5 & 9.39 & 2 & 1 & 0.22 \\
6 & 7.01 & 0 & 2 & 0.29 \\
7 & 6.76 & 1 & 2 & 0.28 \\
8 & 6.30 & 2 & 2 & 0.26 \\
\hline
\end{tabular}

Now we are to consider a structure of level oscillations in more details. All level isolines of the first and the second type seiches are parallel. At the same time the isolines of the first type seiches are parallel to the $y$-axis, and the isolines of the second type seiches are parallel to the $x$-axis. Therefore, the areas with the maximum level deviations are situated in the vicinity of segments which are parallel to one of the coordinate axes. Two of these areas necessarily coincide with the side boundary of the basin. What for the third type seiches, only their nodal lines are parallel to coordinate axes. The rest of their isolines are curves which are situated in rectangles formed by intersecting nodal lines. The sizes of areas with the maximum level deviations are significantly smaller than the ones of the first and the second type seiches. For each of three considered types of seiches, in the vicinity of the corner points of the basin there are areas where level deviations are maximal.

Seiche oscillations cause currents covering the entire volume of liquid in the basin. For the first type seiches the motion of liquid is parallel to $x$-axis, and for the second type seiches it is parallel to $y$-axis. The pattern for the third type seiches is more complex than for ones of the first and the second type. These motions take place at various angles to the coordinate axes.

For the first and the second type seiches the areas of the highest current velocities are situated in a vicinity of nodal lines. For the third type seiches, velocity isoline (it has a value for each mode) divides the basin into the cells. The cells with minimum velocity and with the most intensive currents are selected. The location of intensive wave current zones essentially depends on the mode number. There are 
cells with a constant velocity that is about $50 \%$ of the maximum velocity value. The cells, adjacent to the basin corners where the currents have the minimum intensity, are selected for each mode of seiches.

For all three types of seiches occur both converging and diverging flows. Every half-period of corresponding mode wave current directions are reversed. Velocity module increases from zero to the maximum value during the first halfperiod, and then it decreases down to zero during the next half-period.

Seiche-like oscillations. We are to consider an interaction of two modes of seiche oscillations at the example of superposition $\zeta_{01}$ and $\zeta_{10}$.

In Fig. 1, $a$ the maximum values of level deviation $\zeta_{01}+\zeta_{10}$ over the time period $3 \tau_{10}$ with $\Delta t$ step, where $\tau_{10}$ is a period of the first mode of seiche oscillations, $\Delta t=\tau_{10} / 20$, are represented the for entire basin. At the same time level deviation amplitudes of interacting modes at the initial moment of time are equal to $0.3 \mathrm{~m}$.
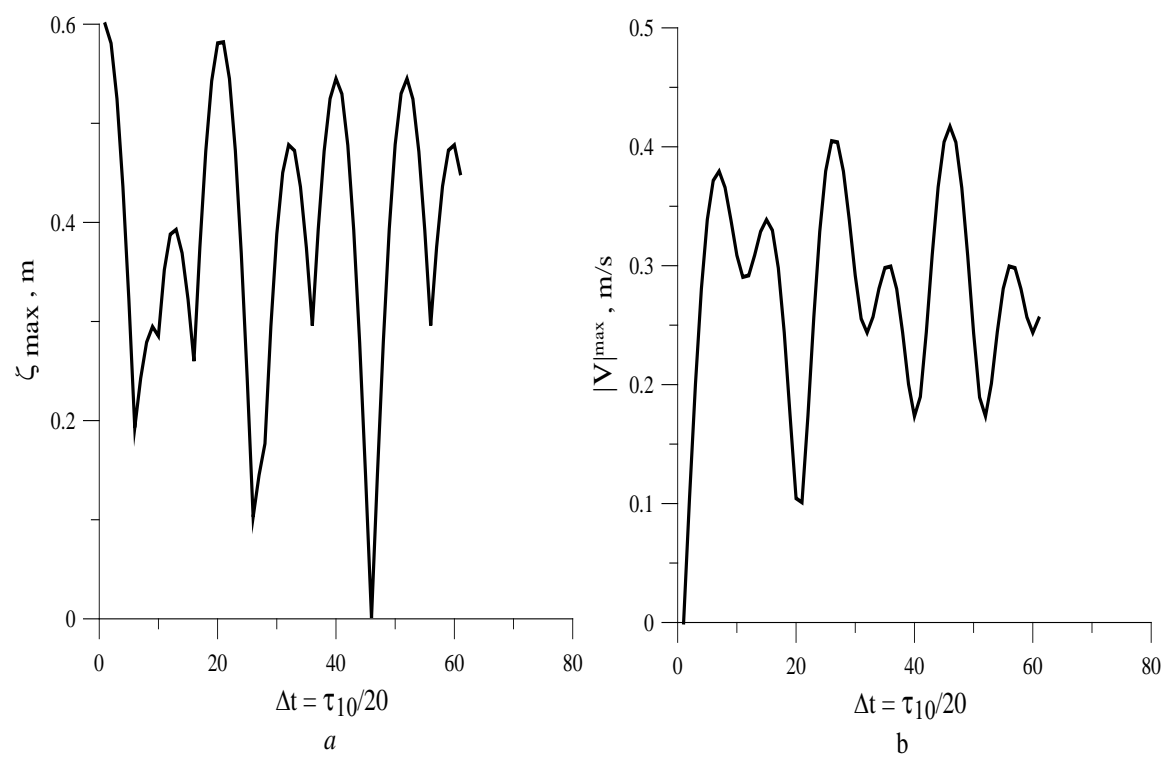

Fig. 1. Time dependence of free surface deviation maximums and wave current velocity module: $a-$ $\zeta_{01}+\zeta_{10}, b-\left|\mathbf{V}_{01}+\mathbf{V}_{10}\right|$

With $t=0$ the deviation of level reaches maximum and makes up $0.6 \mathrm{~m}$. In the course of time the value of maximum decreases, reaches $0.24 \mathrm{~m}$ in $3 \Delta t$ $(3.78 \mathrm{~h})$, and then increases up to $0.39 \mathrm{~m}$ by $6 \Delta t(7.56 \mathrm{~h})$ time point. Afterwards, the value of maximum again decreases down to $0.38 \mathrm{~m}$ at $t=7 \Delta t(8.82 \mathrm{~h})$, and then increases up to 0.58 with $t=10 \Delta t(12.6 \mathrm{~h})$. Analogous level oscillations take place in the next time periods $\left(\tau_{10}, 2 \tau_{10}\right]$ and $\left(2 \tau_{10}, 3 \tau_{10}\right]$. Thus, the maximum of level execute two oscillations during the time period equal to $\tau_{10}$. This is affected by more short-period mode $\left(\tau_{01} / \tau_{10}=0.55\right)$. The calculations revealed the fact that during the interaction of two modes maximum amplitude of resultant wave can be nearly equal to the sum of the amplitudes of interacting modes. In this case 
maximum amplitude of resultant wave reached $98 \%$ of possible maximum in the time point equal to $20 \Delta t(25.2 \mathrm{~h})$ and $88 \%$ of possible maximum in the time point equal to $40 \Delta t(56.7 \mathrm{~h})$. It should be also pointed out that in the calculating time interval the maximum of resultant wave amplitude exceeded $10 \mathrm{~cm}$, except for the narrow time interval in the vicinity of $45 \Delta t(56.7 \mathrm{~h})$ time point where the maximum was equal to zero. The values of maximum level elevation and lowering are equal in modulus at that.

Now we consider how the interaction of two modes affects liquid level oscillations in the basin. In Fig. 2 the isolines of resultant oscillation level $\zeta_{01}+\zeta_{10}$ for different time points of interval, which is equal to $\tau_{10}$, for the case when level deviation amplitudes of interacting modes make up $\zeta_{001}=\zeta_{010}=0.3 \mathrm{~m}$ at the initial time point are represented. At time point $t=0$ (Fig. 2, $a$ ) $\zeta_{\max }=0.6 \mathrm{~m}$, at $t=\tau_{10} / 2$ (Fig 2, b) $\zeta_{\text {max }}=0.29 \mathrm{~m}$ and at $t=\tau_{10}$ (Fig. 2, c) $\zeta_{\text {max }}=0.58 \mathrm{~m}$.

As is evident from this figure, the resultant oscillation has only one nodal line which changes its position with time turning anticlockwise around the center of the basin. After a time period (which is equal to the period of longitudinal uninodal seiche $\tau_{10}$ ) the nodal line turns $90^{\circ}$. Maximum level deviations move in a similar way. In this case, minimum and maximum deviations are equal in modulus in each time point.

The cases when $\zeta_{001}>\zeta_{010}, \zeta_{001}<\zeta_{010}$ were also considered. It is found that a difference of amplitudes has no effect on motion pattern. Only the initial position of this nodal line is changed. If $\zeta_{001}>\zeta_{010}$, then it is shifted anticlockwise comparing with the position when $\zeta_{001}=\zeta_{010}$. If $\zeta_{001}<\zeta_{010}$, then it is shifted clockwise.

Thus, the interaction of two seiche oscillation modes results in a formation of seiche-like oscillation which has one nodal line that turns anticlockwise with time around the center of the basin.

Maximum values of wave current velocity modulus $\left|\mathbf{V}_{01}+\mathbf{V}_{10}\right|$ in time interval with $3 \tau_{10}$ duration are represented in Fig $1, b$. Level deviation amplitudes of the both modes are equal to $0.3 \mathrm{~m}$ at the initial time point. The calculation results demonstrated that the velocity modulus maximum value over the calculating period is $0.42 \mathrm{~m} / \mathrm{s}$. It makes $72 \%$ of sum of maximum velocity amplitudes of the both seiches and it is reached at $26 \Delta t(32.76 \mathrm{~h})$ and $48 \Delta t(60.48 \mathrm{~h})$ time points. A local maximum equal to $0.38 \mathrm{~m} / \mathrm{s}$ ( $66 \%$ of maximum possible value) also occurs at $t=8 \Delta t(10.08 \mathrm{~h})$ time point. The maximum of velocity modulus makes two oscillations during $\tau_{10}$ time period. The maximum of velocity modulus exceeds $10 \mathrm{~m} / \mathrm{s}$ at $0-3 \tau_{10}$ time interval, except for a small segment in the vicinity of time point $t=0$ where wave current velocity is equal to zero. Thus, the velocity modulus doesn't exceed $72 \%$ of maximum possible value and becomes zero just once unlike $3 \tau_{10}$ level deviation for the calculating period. 

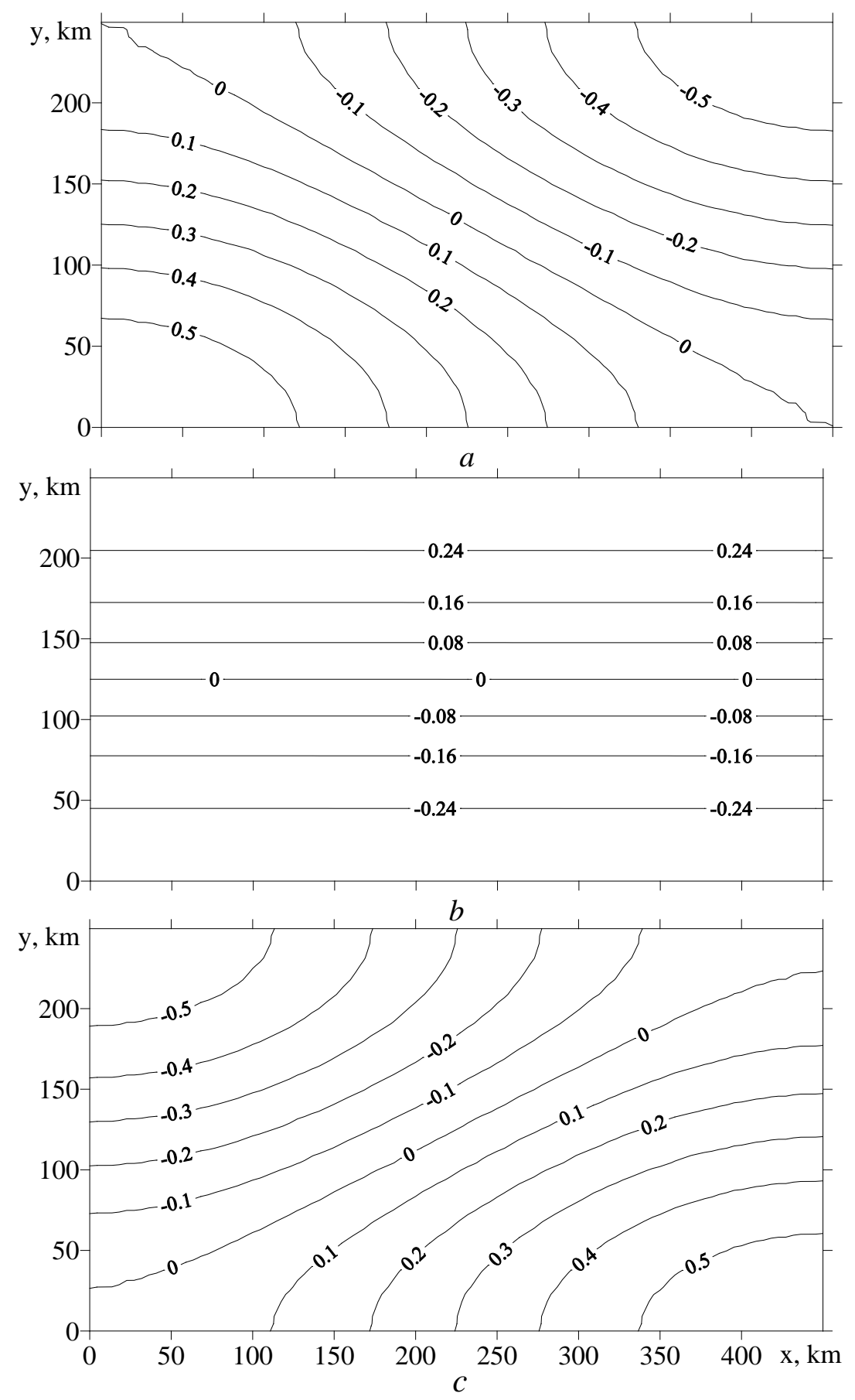

Fig. 2. Isolines of liquid resultant oscillation in the basin $\zeta_{01}+\zeta_{10}: a-t=0, b-t=\tau_{10} / 2$, c$t=\tau_{10}$

In Fig. 3 the vector fields of wave current velocity $\mathbf{V}_{01}+\mathbf{V}_{10}$ for $t=0.3 \tau_{10}$ and $t=0.5 \tau_{10}$ time points are represented. They illustrate the fact that an PHYSICAL OCEANOGRAPHY NO. 2 (2016) 
interaction of two seiche modes results in formation of wave current system. It fundamentally differs from the wave currents that occur for single seiche modes. The direction of currents of the considered seiche-like oscillations constantly changes with time turning clockwise. Counter and divergent flows are absent at that.

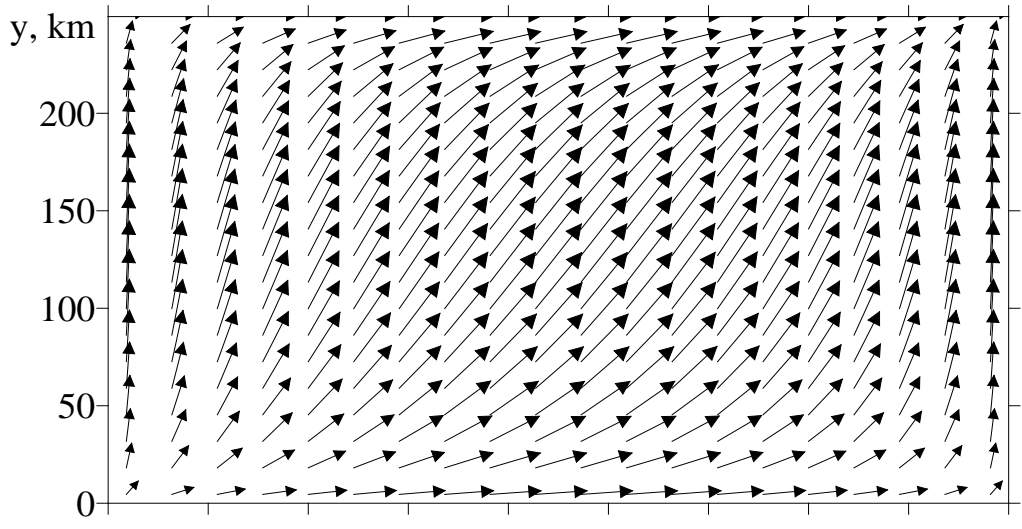

$a$

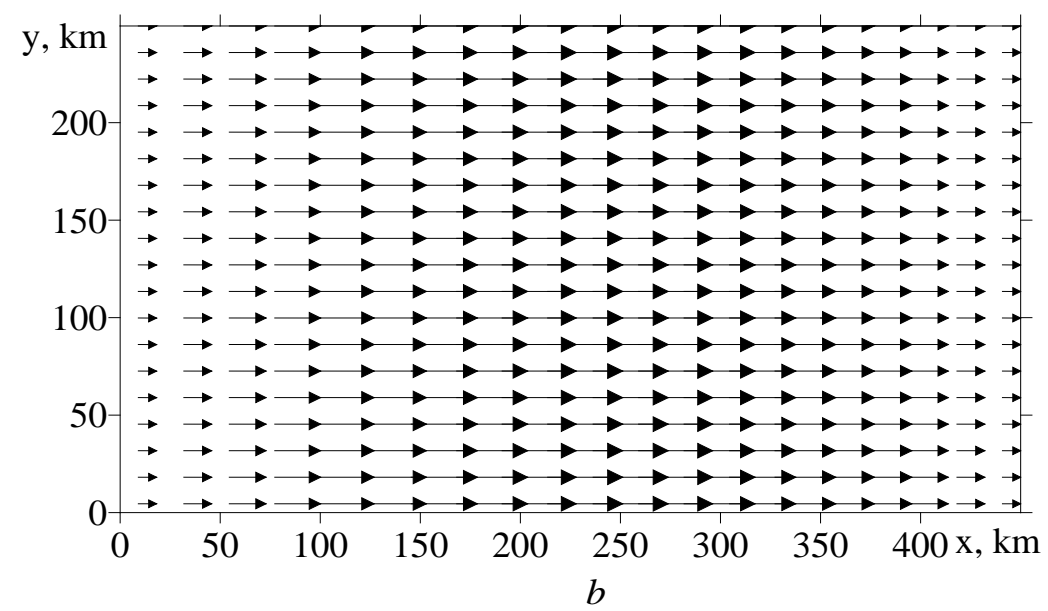

Fig. 3. Vector fields of wave current velocity $\mathbf{V}_{01}+\mathbf{V}_{10}: a-t=0,3 \tau_{10}, b-t=0,5 \tau_{10}$

\section{Conclusions.}

1. The interaction of two seiche modes results in a formation of non-periodic seiche-like oscillation which has one nodal line that is turning in anticlockwise direction with time around the center of the basin.

2. Maximum level elevations in separated parts of the basin waters may approach the maximum possible values which are equal to the sum of interacting wave amplitudes.

3. The maximum value of wave current velocity modulus in all considered cases is under the maximum possible value and doesn't exceed $72 \%$ of it.

4. Wave currents for seiche-like oscillations are fundamentally different from the wave currents that occur for separated seiches. Under the seiche oscillations, 
the direction of currents is constant during a half-period and then it reverses. The presence of counter and divergent flows is also characteristic of the seiches. In case of seiche-like oscillations, the direction of currents of the considered seiche-like oscillations constantly changes with time turning clockwise. Counter and divergent flows are absent.

\section{REFERENCES}

1. 1980, "Okeanograficheskaya entsiklopediya [Oceanographic Encyclopedia]", Leningrad, Gidrometeoizdat, 304 p. (in Russian).

2. $\quad$ Darvin, D., 1961, "Prilivy i rodstvennye im yavleniya $v$ solnechnoj sisteme [Tides and Related Phenomena in the Solar System]”, Moscow, Nauka, 252 p. (in Russian).

3. Labzovskij, N.A., 1971, "Neperiodicheskie kolebaniya urovnya morya”, Leningrad, Gidrometeoizdat, 237 p. (in Russian).

4. $\quad$ Eremeev, V.N., Konovalov, A.V. \& Manilyuk, Yu.V. [et al.], 2000, "Modelirovanie dlinnyh voln v Azovskom more vyzyvaemyh prohozhdeniem ciklonov [Modeling of long waves caused by passage of cyclones in the Sea of Azov]”, Okeanologiya, no. 5, pp. 658-665 (in Russian).

5. Dotsenko, S.F., Miklashevskaya, N.A., 2007, "Generatsiya seysh pri peremeshchenii baricheskikh obrazovaniy [Seiche generation during the movement of baric formations]", Morskoy gidrofizicheskiy zhurnal, no. 6, pp. 3-13 (in Russian).

6. Matishov, G.G., Inzhebeykin, Yu.I., 2009, "Chislennoe issledovanie seyshevykh kolebaniy urovnya Azovskogo morya [Numerical study of level seiche-like oscillations of the Sea of Azov]”, Okeanologiya, no. 4, pp. 485-493 (in Russian).

7. Cherkesov, L.V., Shul'ga, T.Ya., 2015 “Chislennyy analiz prostranstvennoy struktury svobodnykh kolebaniy $v$ Azovskom more [Numerical analysis of free oscilation spatial structure in the Sea of Azov]", Ekologiya, ekonomika, informatika, Sb. statey v 3 tomakh, vol. 2, Sistemnyy analiz i modelirovanie ekonomicheskikh i ekologicheskikh system, Rostov-naDonu, Izd-vo Yuzhnogo federal'nogo un-ta, pp. 689-699 (in Russian).

8. Ivanov, V.A., Yankovskiy, A.E., 1992, "Dlinnovolnovye dvizheniya v Chernom more [LongWave Motion in the Black Sea]”, Kiev, Naukova dumka, 112 p. (in Russian).

9. Maniliuk, Yu.V., Cherkesov, L.V., 1994, "Matematicheskoe modelirovanie seyshevykh kolebaniy $v$ Azovskom more na osnove metoda konechnykh elementov [Mathematical modeling of seiche oscillations in the Sea of Azov based on the finite element method]", Morskoy gidrofizicheskiy zhurnal, no. 5, pp. 3-8 (in Russian).

10. Rabinovich, B.I., Levyant, A.S., 1990, “Chislennoe reshenie zadachi rascheta seysh na osnove RT-algoritma konformnogo otobrazheniya [Numerical solution of seiche calculation problem on the basis of RT-algorithm conformal mapping]", Prirodnye katastrofy $i$ stikhiynye bedstviya v Dal'nevostochnom regione, vol. 2, Vladivostok, DVO AN SSSR, pp. 328-342 (in Russian).

11. Lamb, D., 1947, “Gidrodinamika [Hydrodynamics]”, Moscow, Gostekhizdat, 948 p. (in Russian).

12. Kochin, N.E., Kibel, I.A. \& Roze, N.V., 1956, “Teoreticheskaya gidromekhanika. T. 1 [Theoretical Hydromechanics]”, Moscow, Gostekhizdat, 560 p. (in Russian).

13. Rabinovich, A.B., 2009, "Seiches and Harbor Oscillations (Chapter 9). Handbook of Coastal and Ocean Engineering”, Ed. Y.C. Kim, Singapoure, World Scientific Publ., pp. 193-236.

14. Dotsenko, S.F., Miklashevskaya, N.A., 2008, "Generatsiya seysh $v$ ogranichennykh basseynakh peremeshchayushchimisya baricheskimi frontami [Generation of Seiches in Bounded Basins by Moving Baric Fronts]”, Morskoy gidrofizicheskiy zhurnal, no. 2, pp. 3-19 (in Russian).

15. Sretenskiy, L.N., 1977, “Teoriya volnovykh dvizheniy zhidkosti [Theory of Wave Motion of a Liquid]”, Moscow, Nauka, 815 p. (in Russian).

PHYSICAL OCEANOGRAPHY NO. 2 (2016) 